\title{
miR-337-3p inhibits gastric tumor metastasis by targeting ARHGAP10
}

\author{
ZISHU WANG ${ }^{1 *}$, LUN YAO $^{2 *}$, YU LI $^{1}$, BO HAO $^{3}$, MINGXI WANG $^{1}$, JUNBIN WANG $^{1}$, \\ WEI GU ${ }^{2}$, HUIHUI ZHAN ${ }^{2}$, GUOQUAN LIU ${ }^{2}$ and QIONG WU ${ }^{1}$ \\ ${ }^{1}$ Department of Medical Oncology, The First Affiliated Hospital of Bengbu Medical College, \\ Anhui Province Key Laboratory of Translational Cancer Research, Bengbu, Anhui 233004; \\ ${ }^{2}$ Department of Basic Veterinary Medicine, College of Animal Science and Veterinary Medicine, \\ Huazhong Agricultural University, Wuhan, Hubei 430070; ${ }^{3}$ Department of Gastrointestinal Surgery, \\ The First Affiliated Hospital of Bengbu Medical College, Bengbu, Anhui 233004, P.R. China
}

Received July 12, 2018; Accepted April 17, 2019

DOI: $10.3892 / \mathrm{mmr} .2019 .10856$

\begin{abstract}
Several microRNAs (miRNAs) are known as regulatory molecules involved in gastric tumor metastasis. The expression of miR-337-3p was revealed to be downregulated in metastatic gastric tumor cells. Overexpression of miR-337-3p in gastric cancer cells resulted in the reduction of their invasive abilities. To characterize the functions of miR-337-3p, miR-337-3p was expressed in a metastatic lymph node-derived gastric tumor cell line, SGC-7901. Overexpression of $\mathrm{miR}-337-3 \mathrm{p}$ reduced the viability of cells but had no effects on the cell cycle. Wound healing and Transwell migration assays revealed that miR-337-3p inhibited the migration capacity of cells. miR-337-3p was capable of binding to the 3'-untranslated region of a cytoskeleton-associated molecule, ARHGAP10. Overexpression of $\mathrm{miR}-337-3 \mathrm{p}$ reduced the mRNA and protein levels of ARHGAP10 and the co-expression of ARHGAP10 and miR-337-3p resulted in the recovery of cell migration capacity. Furthermore, the injection of miR-337-3p-overexpressing SGC-7901 cells into an immunodeficient mouse model resulted in a decrease in tumor metastasis in the liver and lungs. The present results indicated that miR-337-3p
\end{abstract}

Correspondence to: Dr Zishu Wang or Dr Qiong Wu, Department of Medical Oncology, The First Affiliated Hospital of Bengbu Medical College, Anhui Province Key Laboratory of Translational Cancer Research, 287 Changhuai Road, Bengbu, Anhui 233004, P.R. China

E-mail: zishuwang@163.com

E-mail: qiongwu68@aliyun.com

*Co-first authorship

Abbreviations: miRNA, microRNA; 3'-UTR, 3'-untranslated region; MMP14, matrix metalloproteinase 14

Key words: miR-337-3p, ARHGAP10, gastric tumor, migration, metastasis regulates gastric tumor metastasis by targeting the cytoskeleton-associated protein ARHGAP10.

\section{Introduction}

Tumor metastasis is characterized with the spread of tumor cells to different tissues and organs from the primary tumor site, resulting in the formation of secondary new tumors (1). Hence, tumor metastasis is a major reason for cancer-related high mortality. Several approaches have been directed to interrupt the metastasis of primary tumors for cancer treatment (1). Considering the complexity and multi-steps involved in tumor metastasis, the detailed mechanisms underlying this process are yet to be completely understood. The process of tumor metastasis broadly comprises three sequential events, namely, invasion, intravasation, and extravasation (2). During invasion, the tumor cells dissociate from the primary tumor cells, dissolve the basal membrane and extracellular matrix, and initiate the upregulation or downregulation of proteins controlling tumor cell motility and migration (3).

MicroRNAs (miRNAs) are small-noncoding RNA molecules that play regulatory roles in multiple cellular functions by downregulating the expression of certain genes (4). Recent studies have identified miRNAs as a new class of molecules associated with tumor metastasis and revealed their roles in the regulation of tumor metastasis (5). In gastric cancer, several miRNAs have been recognized as regulatory molecules involved in tumor cell invasion and metastasis. miR-337-3p expression has been revealed to be downregulated in metastatic tissues when compared to primary gastric cancer tissues (6). Furthermore, the overexpression of miR-337-3p in gastric cancer cells has been revealed to result in the reduction of their invasion ability (6). Recent evidence indicates that miR-337-3p may bind to the promoter region and suppress the transcription of matrix metalloproteinase 14 (MMP14) in both gastric tumor and neuroblastoma cells $(7,8)$. The mechanism of the function of miR-337-3p in invasion is not yet clear. Whether miR-337-3p targets cytoskeleton-associated molecules in invasive gastric cancer is also unknown. In the 
present study, the major target molecules of miR-337-3p in tumor invasion were investigated.

ARHGAP10, also known as ARHGAP21, was originally identified as a gene located on the human chromosome 10 . ARHGAP10, a cytoskeletal regulatory protein, is known to encode a Rho-GTPase-activating protein owing to its Rho-GAP domain (9). It negatively regulates the small $\mathrm{G}$ protein Rho- and Cdc42-mediated downstream signal transduction $(10,11)$. ARHGAP10 overexpression has been revealed to disrupt stress fiber formation in some cells (12). A recent study suggested that ARHGAP10 is involved in the regulation of tumor cell migration (13). In the present study, ARHGAP10 was identified as a molecular target of miR-337-3p and its role was demonstrated in mediating the regulatory effects of miR-337-3p on gastric cancer cell migration and invasion.

\section{Materials and methods}

Cell culture and transfection. Gastric cancer SGC-7901 cells, originally purchased from the Cell Bank of the Chinese Academy of Sciences, were maintained in Roswell Park Memorial Institute (RPMI)-1640 medium (Gibco; Thermo Fisher Scientific, Inc.) supplemented with $10 \%$ fetal bovine serum (FBS; Gibco; Thermo Fisher Scientific), $2 \mathrm{mM}$ L-glutamine (Gibco; Thermo Fisher Scientific), $100 \mathrm{U} / \mathrm{ml}$ penicillin and $100 \mu \mathrm{g} / \mathrm{ml}$ streptomycin (Gibco; Thermo Fisher Scientific). 293T cells, originally purchased from the Cell Bank of the Chinese Academy of Sciences, were maintained in high glucose-Dulbecco's Modified Eagle's medium (DMEM; Gibco; Thermo Fisher Scientific) with no glutamine and supplemented with $10 \%$ FBS, 2 mM L-glutamine, penicillin (100 U/ml), and streptomycin $(100 \mu \mathrm{g} / \mathrm{ml})$. Both cell lines were cultured in 6-well plates in humidified air supplemented with $5 \% \mathrm{CO}_{2}$ at $37^{\circ} \mathrm{C}$.

SGC-7901 cells were seeded in 6-well plates and transfected with miRNAs and cDNA after reaching $80 \%$ confluency. Lipofectamine 2000 transfection reagent (Invitrogen; Thermo Fisher Scientific, Inc.) was used for the transfection of miRNAs and cDNA. For the expression of miRNAs, miR-337-3p or miR-337-3p inhibitor and respective control miR-NC and inhibitor NC (Shanghai GenePharma Co., Ltd.) at a final concentration of $50 \mathrm{nM}$ were used for transfection. The sequences were as follows: miR-337-3p mimics, sense, 5'-CUC CUAUAUGAUGCCUUUCUUC-3' and antisense, 5'-AGA AAGGCAUCAUAUAGGAGUU-3'; miR-NC, sense, 5'-UUC UCCGAACGUGUCACGUTT-3' and antisense, 5'-ACG UGACACGUUCGGAGAATT-3'; miRNA-337-3p inhibitor, 5'-GAAGAAAGGCAUCAUAUAGGAG-3'; and inhibitor NC, 5'-CAGUACUUUUGUGUAGUACAA-3'.

ARHGAP10 cDNA was subcloned in the expression vector pcDNA3.1 (Invitrogen; Thermo Fisher Scientific, Inc.) and confirmed by sequencing. For the expression of cDNA, $2.5 \mathrm{ng} /$ well of ARHGAP10 cDNA or pcDNA3.1 were added. The cells were incubated for 24-48 $\mathrm{h}$ in humidified air supplemented with $5 \% \mathrm{CO}_{2}$ at $37^{\circ} \mathrm{C}$. Then, the transfected cells were analyzed.

Small interfering RNA (siRNA) specific for ARGHAP10 (siRNA-ARHGAP10; $20 \mu \mathrm{mol} / \mathrm{l}$; Guangzhou Ribobio Co., Ltd.) was transfected into SGC7901 cells using Lipofectamine 2000. The si-ARHGAP10 targeting sequence was 5'-CTGCTA
CTGTAGCGGACAA-3'. Negative control siRNA (siRNA-NC; cat. no. siN0000001-1-5; Guangzhou Ribobio Co., Ltd.) was used as a control. At 24-48 h following transfection, the transfected cells were analyzed.

Cell viability and cell cycle analysis. SGC-7901 cells were seeded in 96-well plates and transfected with miRNAs after reaching $80 \%$ confluency. After $24 \mathrm{~h}$, the cells were incubated with Cell Counting Kit-8 (CCK-8; Biosharp) for $4 \mathrm{~h}$ and the absorbance at $450 \mathrm{~nm}$ was assessed using a plate reader. For cell cycle analysis, SGC-7901 cells were seeded in 6-well plates and transfected with miRNAs (miR-337-3p, miR-337-3p inhibitor, miR-NC and inhibitor NC.). After $24 \mathrm{~h}$ of transfection, the cells were harvested and washed with cold phosphate-buffered saline (PBS; HyClone; GE Healthcare Life Sciences). The cells were fixed with cold $95 \%$ ethanol at $4^{\circ} \mathrm{C}$ overnight, followed by staining with $50 \mu \mathrm{g} / \mathrm{ml}$ propidium iodide (CWBio) and $10 \mu \mathrm{g} / \mathrm{ml}$ RNAse (Takara Biotechnology Co., Ltd.) at $37^{\circ} \mathrm{C}$ in the dark for $30 \mathrm{~min}$. Cell cycle analysis was carried out with flow cytometry. Data were analyzed using FlowJo version 7.6 (FlowJo LLC).

Wound healing assay. The transfected SGC-7901 cells were seeded into 6-well culture plates. The cells reached $\sim 80 \%$ confluency after $24 \mathrm{~h}$ of cutlure. A wound was gently created by scratching the monolayer with a $10 \mu l$ pipette tip. After scratching, the cells were washed twice with medium to remove the detached cells. Images were captured. The cells were incubated in 1\% FBS-supplemented RPMI-1640 culture medium for an additional $48 \mathrm{~h}$. Images were acquired and quantitative analysis was performed with software Image-Pro Plus 6.0 (Media Cybernetics, Inc.).

Transwell migration and invasion assays. Gastric tumor cell migration and invasion were assessed using a two-chamber system. The upper compartment was inserted into the lower compartment of BD BioCoat control inserts (Discovery Labware; BD Biosciences). The invasion assay was conducted in a Transwell format with Matrigel in the upper chamber. A Transwell-Matrigel insert was used for the invasion assay. The same procedure was conducted for the migration assay without the use of Matrigel. After transfection, the cells were cultured in serum-free RPMI-1640 culture medium for $12 \mathrm{~h}$. Cells [5×10 in $0.1 \mathrm{ml}$ of serum-free medium containing $1 \%$ bovine serum albumin (BSA; Gibco; Thermo Fisher Scientific, Inc.)] were seeded into the upper compartment, while the lower compartment was filled with normal culture medium supplemented with $20 \%$ FBS. After incubation for $24 \mathrm{~h}$, the cells were wiped away from the upper surface, and the migrated cells on the lower surface were fixed and stained with $0.1 \% \mathrm{~g} / \mathrm{ml}$ crystal violet (Beijing Solarbio Science \& Technology Co., Ltd.) at $25^{\circ} \mathrm{C}$ for 20 mins. The number of cells that completely invaded across the filter was determined in five random fields for each experiment using EVOS M7000 Imaging System (Thermo Fisher Scientific, Inc.; magnification, x100). Each condition was assayed in triplicates, and each experiment was repeated at least thrice.

Bioinformatic analysis. Potential targets of miR-337 were analyzed using TargetScan version 7.2 (http://www. targetscan.org/vert_72/). 
Tumor metastasis assay in an immunodeficient mouse model. A total of 20 female NOD-Prkdc ${ }^{\text {scid }} I l 2 r g^{\text {null }}$ mice at 5 weeks of age (weighing 18-22 g) were purchased from Beijing VITALSTAR Biotechnology Co., Ltd. The animals were maintained in an ACS OptiMICE EVC animal care system (Animal Care Systems Inc.). All mice were housed in rooms with a 12-h day/night cycle at $22^{\circ} \mathrm{C}$ and had free access to standard chow (Sebiona). Cages, food, and bedding were sterilized by autoclaving. All animal experiments were performed according to the guidelines of the Laboratory Animal Ethics Committee of Huazhong Agriculture University, approved by the Laboratory Animal Centre, Huazhong Agriculture University (HZAHMD-2016-037). Mice were divided into four groups (5 mice/group) for tail intravenous injection. SGC-7901 cells were transfected with miRNAs (miR-337-3p, miR-337-3p inhibitor, miR-NC and inhibitor NC) and harvested $12 \mathrm{~h}$ after transfection. Cells $\left(2 \times 10^{6}\right.$ in $0.1 \mathrm{ml}$ PBS $)$ were injected into each mouse via tail vein. Mice were maintained under these conditions for 5 weeks, and were sacrificed after these 5 weeks by carbon dioxide asphyxiation.

Histological assay. Lung and liver tissues were collected and fixed with $10 \%$ buffered formalin at $25^{\circ} \mathrm{C}$ for $48 \mathrm{~h}$, perfused and dissected, and paraffin-embedded. Sections (6-mm thickness) were stained with hematoxylin and eosin (H\&E) using a Hematoxylin and Eosin Staining kit (Beyotime Institute of Biotechnology) in accordance with the manufacturer's protocols. To evaluate the expression of ARHGAP10 in lung tumor foci, immunohistochemical experiments were conducted using a specific polyclonal anti-ARHGAP10 antibody $(1: 1,000$; cat. no. 55139-1-AP, ProteinTech Group, Inc.). All sections were analyzed with a routine light microscope (Nikon Corporation).

RNA isolation and reverse transcription-quantitative polymerase chain reaction ( $q P C R$ ). For the detection of mRNA expression, total RNA was isolated from cells and tissues using TRIzol (Invitrogen) following the manufacturer's protocol. The quantification of the extracted RNA was performed with NanoDrop 2000 spectrophotometer. Approximately $1 \mathrm{mg}$ of total RNA was reverse-transcribed using a Two-Step MMLV RT-PCR kit from GeneMark, and qPCR was performed to determine the expression level of ARHGAP10 on a Roche LightCycler ${ }^{\circledR} 96$ using SYBR Green Real-Time PCR Master Mix from GeneMark according to the manufacturer's instructions. The thermocycling conditions were denaturation at $95^{\circ} \mathrm{C}$ for $30 \mathrm{sec}$, then 35 cycles of denaturation at $95^{\circ} \mathrm{C}$ for $5 \mathrm{sec}$, annealing at $56^{\circ} \mathrm{C}$ for $30 \mathrm{sec}$ and elongation at $72^{\circ} \mathrm{C}$ for $30 \mathrm{sec}$, followed by a $5 \mathrm{~min}$ extension at $72^{\circ} \mathrm{C}$. The relative expression of miRNAs and mRNA were determined using the $2^{-\Delta \Delta \mathrm{Cq}}$ quantification method (14). Three independent experiments were replicated. The primers specific for ARHGAP10 were 5'-ACTGAAACCCTGATTAAACC-3' (forward) and 5'-ATC TGCCTCTTGTAAATGTG-3' (reverse), while those for glyceraldehyde 3-phosphate dehydrogenase (GAPDH) were 5'-CACCCACTCCTCCACCTTTG-3' (forward) and 5'-CCA CCACCCTGTTGCTGTAG-3' (reverse).

For miRNA assessment, commercial miRcute miRNA isolation kit, miRcute miRNA First-Strand cDNA Synthesis kit, and miRcute miRNA qPCR detection kit (Tiagen Biotech Co., Ltd.) were used. qPCR was performed using the mature
miR-337-3p sequence as the forward primer along with the universal reverse primer provided with the miRNA qPCR detection kit, and small nuclear RNA U6 served as an internal control. The specific primers for miR-337-3p included 5'-CUCCUA UAUGAUGCCUUUCUUC-3' and 5'-GTGCAGGGTCCG AGGT-3', while those for U6 included 5'-CACCCACTCCTC CACCTTTG-3' and 5'-CCACCACCCTGTTGCTGTAG-3'.

Western blot analysis. SGC-7901 cells were lysed after transfection in $1 \mathrm{ml}$ of ice-cold tissue lysis buffer [Tris-buffered saline, $1.5 \%$ Triton $\mathrm{X}-100,0.5 \%$ deoxycholic acid, $0.1 \%$ sodium dodecyl sulfate (SDS), protease inhibitor cocktail, and $1 \mathrm{mM}$ PMSF]. After centrifugation $\left(12,000 \times \mathrm{g}, 20 \mathrm{~min}, 4^{\circ} \mathrm{C}\right)$, the supernatants were collected and protein concentrations were determined. Protein samples (15 $\mu \mathrm{g}$ per lane) were separated on $10 \%$ SDS polyacrylamide gels and transferred onto nitrocellulose membranes. The blots were blocked with $5 \%$ skimmed milk (Becton, Dickinson and Company) at $25^{\circ} \mathrm{C}$ for $1 \mathrm{~h}$ and incubated with primary antibodies specific for ARHGAP10 (1:1,000; cat. no. 55139-1-AP) and GAPDH $(1: 4,000$; cat. no. 60004-1-Ig; both from ProteinTech Group, Inc.) at $4^{\circ} \mathrm{C}$ overnight. After developing, each blot was washed three times in 1X TBST (Beijing Solarbio Science \& Technology Co., Ltd.). The blots were incubated with secondary antibodies labeled with horseradish peroxidase (ProteinTech Group, Inc.) at $25^{\circ} \mathrm{C}$ for $1 \mathrm{~h}$. HRP-conjugated anti-rabbit (cat. no. SA00001-2) and HRP-conjugated anti-mouse (cat. no. SA00001-1; both from ProteinTech Group, Inc.) antibodies were used at 1:4,000. Signals were detected by enhanced chemiluminescence western blot reagents (Thermo Scientific Scientific, Inc.). ImageJ version 2.1.4.7 (National Institutes of Health) was used for densitometry.

Plasmid construction and luciferase assays. The 3'-untranslated region (UTR) segment of ARHGAP10 predicted to specifically interact with miR-337-3p was subcloned into pMIR-REPORT luciferase vector psiCHECKTM-2 (Applied Biosystems; Thermo Fisher Scientific, Inc.). 293T cells were transfected with wild-type plasmids using Lipofectamine 2000. At $48 \mathrm{~h}$ after transfection, the cells were lysed and the luciferase activity was detected with the Dual-Luciferase reporter assay system (Promega Corporation). Firefly luciferase activity was normalized to Renilla luciferase activity for each sample. psiCHECKTM-2 control plasmid was used for normalization of luciferase values. Each reporter plasmid was transfected at least thrice, and each sample was assayed in triplicates.

Statistical analysis. The results are presented as the mean \pm standard deviation (SD) of three independent experiments. Differences between two groups were compared using a two-tailed paired Student's t-test; one-way analysis of variance (ANOVA) was used for comparisons between multiple groups. The Student-Newman-Keuls test was used as a post hoc test following ANOVA. $\mathrm{P}<0.05$ was considered to indicate a statistically significant difference.

\section{Results}

miR-337-3p affects the viability of gastric cancer cells. To examine the expression level of miR-337-3p after transfection, 

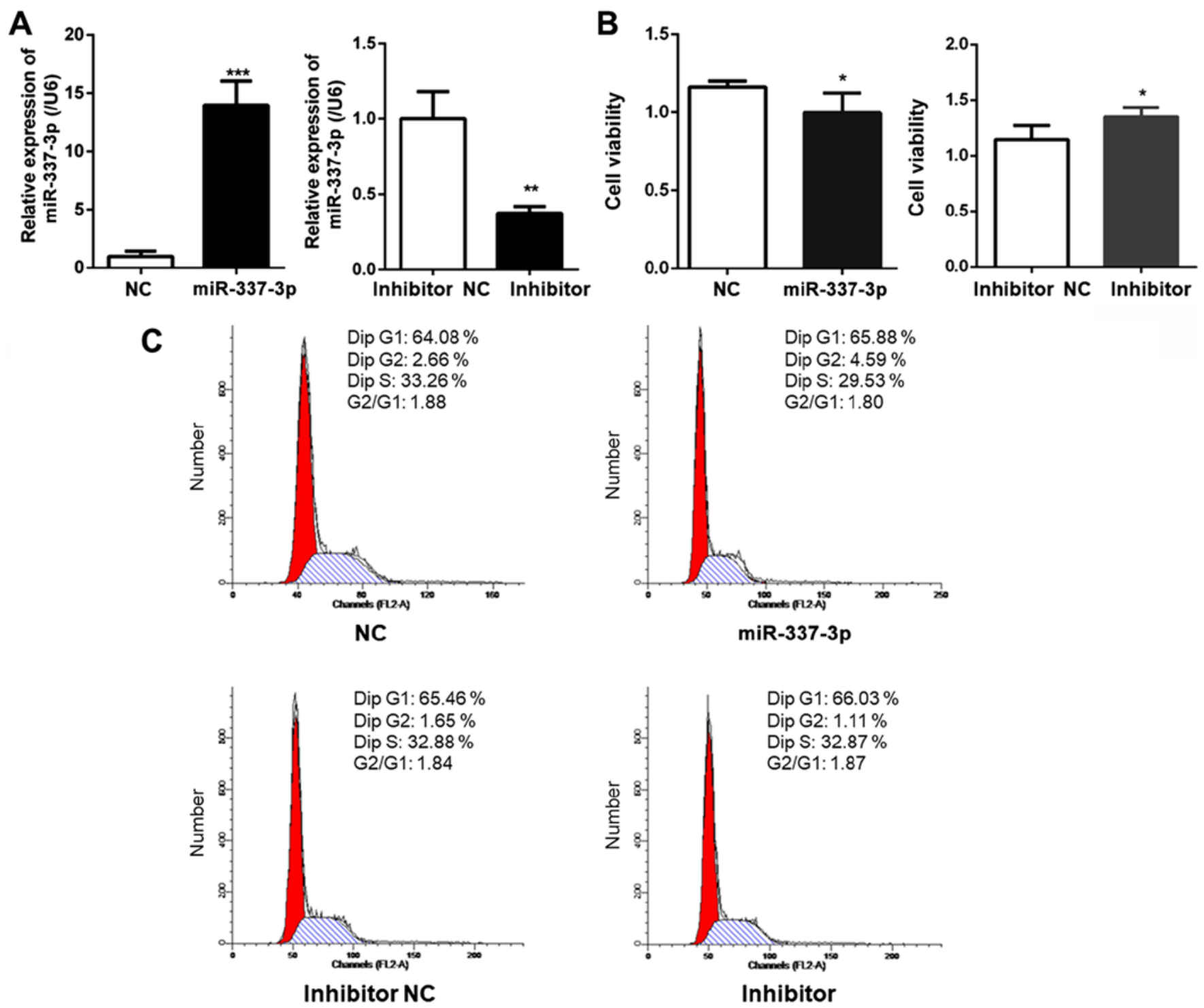

Figure 1. Overexpression of miR-337-3p reduces the viability of metastatic gastric tumor cells but has no effects on the cell cycle. SGC-7901 cells were transfected with control, miR-337-3p mimic, control inhibitor, and miR-337-3p inhibitor, and (A) the relative expression of miR-337-3p was examined with reverse transcription-quantitative PCR. (B) Cell viability was analyzed with a Cell Counting Kit-8 assay and (C) cell cycle analysis was carried out with flow cytometry. The data are expressed as the mean $\pm \mathrm{SD}$ of three independent transfection experiments. ${ }^{*} \mathrm{P}<0.05,{ }^{* *} \mathrm{P}<0.01$ and ${ }^{* * * *} \mathrm{P}<0.001$. miR-337-3p, microRNA-337-3p; NC, negative control.

RT-qPCR analysis was performed. The results revealed the overexpression of miR-337-3p in the transfected cells. The transfection of miR-337-3p inhibitor resulted in the downregulation of miR-337-3p expression (Fig. 1A). The effects of miR-337-3p overexpression on the viability of gastric cancer SGC-7901 cells were also examined. A CCK-8 assay was used to assess SGC-7901 cell viability and it was revealed that the overexpression of miR-337-3p resulted in a decrease in the viability of gastric cancer cells to $<10 \%$ (Fig. 1B). Next, the effects of miR-337-3p expression on the cell cycle of SGC-7901 cells were examined. Flow cytometric analysis revealed that miR-337-3p had no effect on the cell cycle (Fig. 1C). This observation was consistent with one previously reported, wherein miR-337-3p did not affect the proliferation of gastric cancer cells (4). The reduced viability indicated that miR-337-3p may induce apoptosis in gastric cancer cells.
miR-337-3p decreases the motility of gastric cancer cells. The effects of miR-337-3p overexpression on the motility of SGC-7901 cells were examined with a wound healing assay. SGC-7901 cells transfected with miR-337-3p exhibited lower wound healing capacity than the control cells (Fig. 2A), indicating that miR-337-3p inhibits the migration of gastric cancer cells (Fig. 2B). To further confirm the inhibitory effects of miR-337-3p on gastric cancer cell motility, the effects of miR-337-3p overexpression on SGC-7901 motility were investigated in a Transwell migration assay (Fig. 3A). The overexpression of miR-337-3p in SGC-7901 cells resulted in a decrease in their migration through the Transwell, while the inhibition of miR-337-3p expression resulted in an increase in the Transwell migration ability (Fig. 3B).

To better understand the effects of miR-337-3p on gastric tumor metastasis, the role of miR-337-3p in SGC-7901 cell 

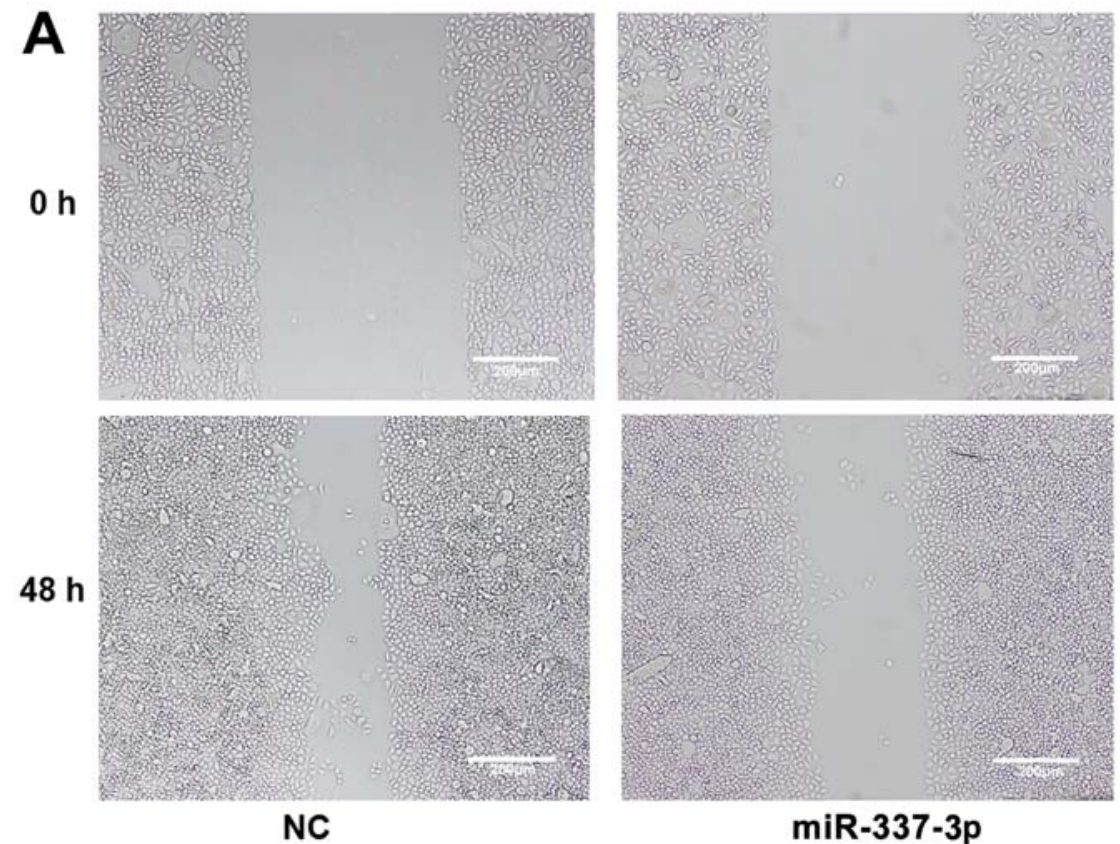

B

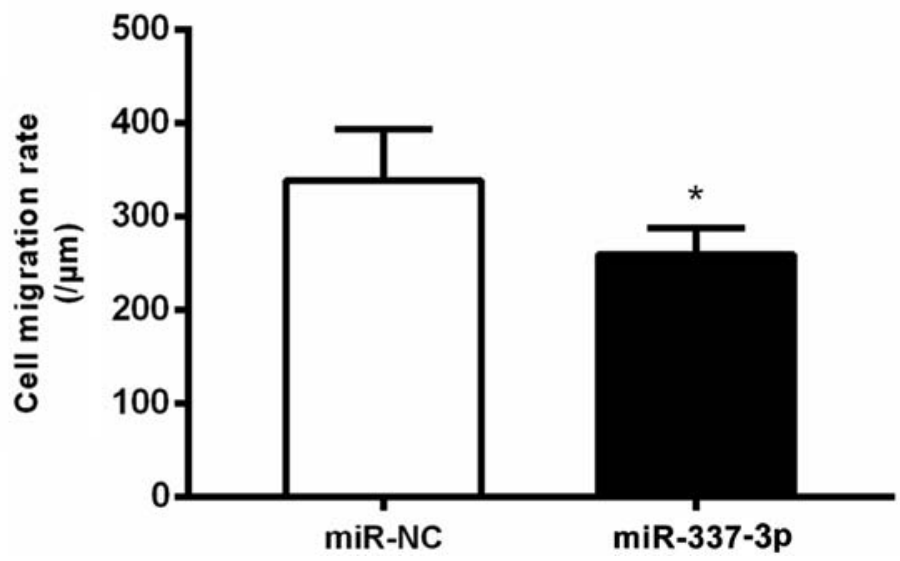

Figure 2. Overexpression of miR-337-3p results in the inhibition of migration and invasion of metastatic gastric tumor cells. SGC-7901 cells were transfected with control, miR-337-3p mimic, control inhibitor, and miR-337-3p inhibitor. The results were amplified 40 times and the cells were subjected to (A) wound healing assays. Scale bar, $200 \mu \mathrm{m}$ (B) The results were statistically summarized. Data are expressed as the mean \pm SD of three independent transfection experiments. ${ }^{*} \mathrm{P}<0.05$. miR, microRNA; NC, negative control.

invasion was examined (Fig. 4A). An invasion assay was conducted in a Transwell format and Matrigel was placed in the upper chamber. Transfection of SGC-7901 cells with miR-337-3p decreased the number of cells in the bottom chamber, indicating that miR-337-3p may inhibit the invasive capacity of gastric cancer cells (Fig. 4B).

ARHGAP10 serves as a target for miR-337-3p. To understand the mechanisms underlying the inhibitory effect of miR-337-3p on gastric cancer cell migration, the target molecules were explored. TargetScan (http://www.targetscan.org/vert_72/) was used to identify ARHGAP10 as a potential target molecule. Three potential miR-337-3p-binding sites were identified at the 3'-UTR of ARHGAP10 mRNA (Fig. 5A). The 3'-UTR of ARHGAP10 was subcloned in a luciferase vector; the luciferase activity assay revealed the ability of miR-337-3p to inhibit ARHGAP10 expression (Fig. 5B). The overexpression of miR-337-3p resulted in a decrease in the expression of ARHGAP10 mRNA, as assessed with qPCR in SGC-7901 cells (Fig. 5C). Western blot analysis revealed that miR-337-3p reduced the protein level of ARHGAP10 in SGC-7901 cells (Fig. 5D). Collectively, these results indicated that miR-337-3p downregulated ARHGAP10 expression by binding to its 3'-UTR.

ARHGAP10 restores the migration capacity of gastric cancer cells. Next, the effects of the overexpression of ARHGAP10 on the migration capacity of gastric cancer cells were examined by a Transwell migration assay. SGC-7901 cells were transfected with pcDNA3.1 or ARHGAP10 overexpression plasmid, and the ARHGAP10 plasmid induced an increase in ARHGAP10 mRNA expression (Fig. 6A). It was observed that the overexpression of $\mathrm{miR}-337-3 \mathrm{p}$ reduced the Transwell migration ability of SGC-7901 cells. Conversely, the overexpression of ARHGAP10 increased the migration of SGC-7901 cells. Furthermore, the co-transfection of miR-337-3p and ARHGAP10 cDNA in SGC-7901 cells abolished the inhibitory effect of miR-337-3p on cell 


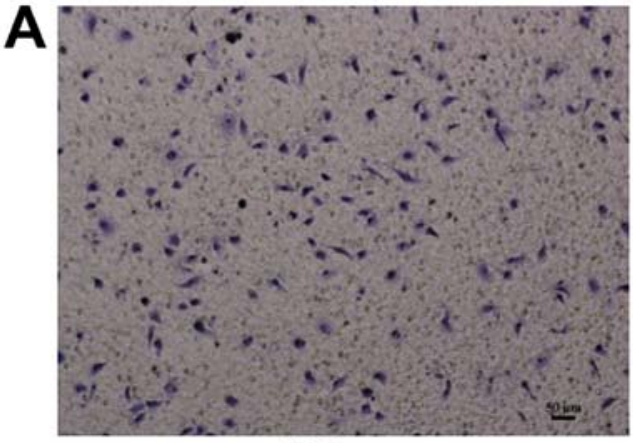

NC

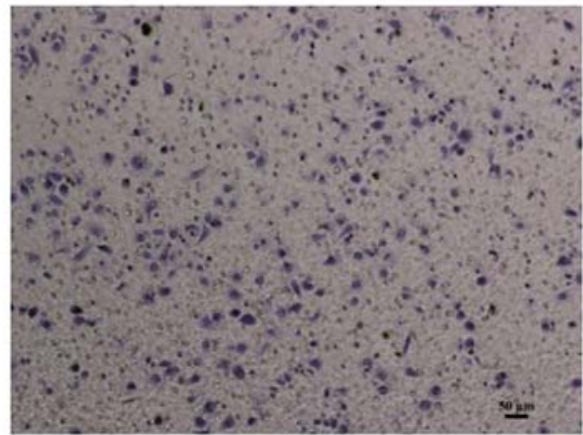

Inhibitor NC

B

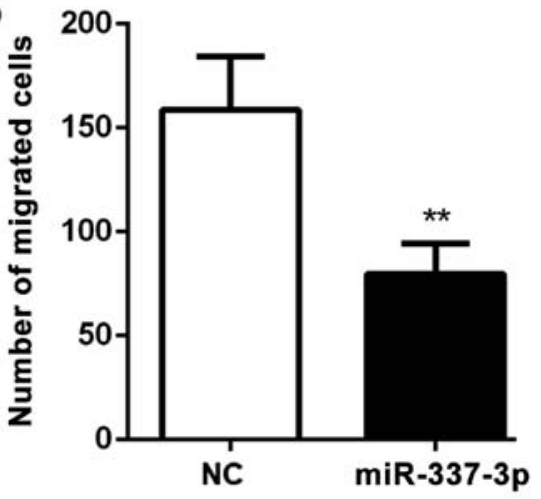

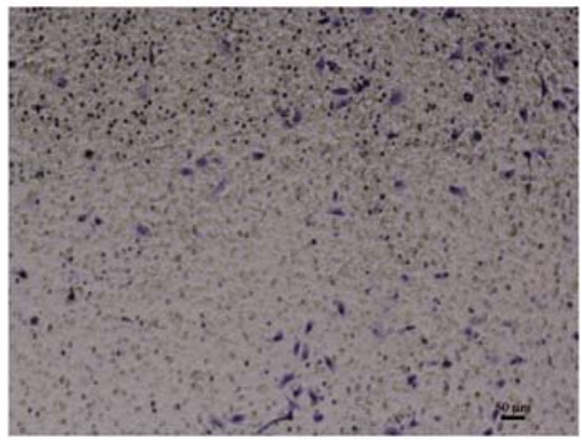

miR-337-3p

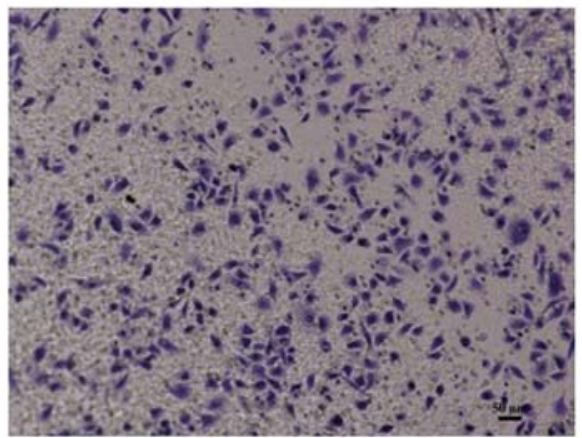

Inhibitor

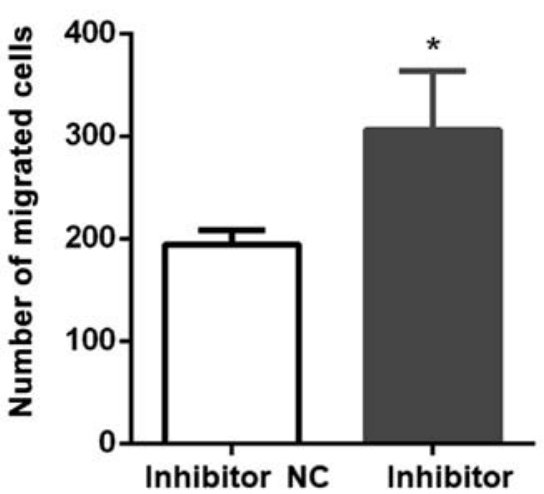

Figure 3. Overexpression of miR-337-3p results in the inhibition of the migration of metastatic gastric tumor cells. SGC-7901 cells were transfected with control, miR-337-3p mimic, control inhibitor, and miR-337-3p inhibitor and subjected to (A) Transwell migration assays. Scale bar, 50 $\mu \mathrm{m}$. (B) The results were statistically summarized. The data are expressed as the mean \pm SD of three independent transfection experiments. ${ }^{*} \mathrm{P}<0.05$ and ${ }^{* *} \mathrm{P}<0.01$. miR-337-3p, microRNA-337-3p; NC, negative control.

migration (Fig. 6B and $\mathrm{C}$ ). These results indicated that miR-337-3p may target and downregulate ARHGAP10 expression to inhibit the migration of gastric cancer cells. To understand the influence of ARHGAP10 on gastric tumor metastasis, SGC-7901 cells were transfected with siRNA-NC and siRNA-ARHGAP10, and the relative expression of ARHGAP10 was examined with qPCR (Fig. 7A). SGC-7901 cells transfected with siRNA-ARHGAP10 revealed a decrease in the wound healing capacity as compared with the control cells (Fig. 7B and C).

miR-337-3p decreases the in vivo metastasis of gastric cancer cells. To understand the role of miR-337-3p in gastric tumor metastasis under in vivo conditions, SGC7901 cells were transfected with the miRNA and injected into NOD-Prkd $c^{\text {scid }} I l 2 r g^{\text {null }}$ mice, which lack T, B, and nature killer cells. After 5 weeks, the mice injected with
miR-337-3p-expressing SGC-7901 cells presented a reduced number of tumor foci in the lungs and liver. Conversely, the injection of SGC-7901 cells transfected with inhibitor resulted in an increase in the number of tumor foci in the lungs and liver (Figs. 8 and 9). To examine the relative expression of miR-337-3p in the lung tumor foci, RT-qPCR analysis was performed. As a result, it was revealed that the overexpression of miR-337-3p was evident from the high expression of miR-337-3p in the lung tumor foci. In addition, the transfection with miR-337-3p inhibitor downregulated the expression of miR-337-3p in the lungs (Fig. 10A). To confirm that ARHGAP10 expression is suppressed by miR-337-3p, ARHGAP10 mRNA expression level was evaluated with RT-qPCR and histological analyses. Overexpression of miR-337-3p decreased the expression of ARHGAP10 mRNA, as assessed by qPCR in SGC-7901 cells from the lung tumor foci (Fig. 10B and C). 


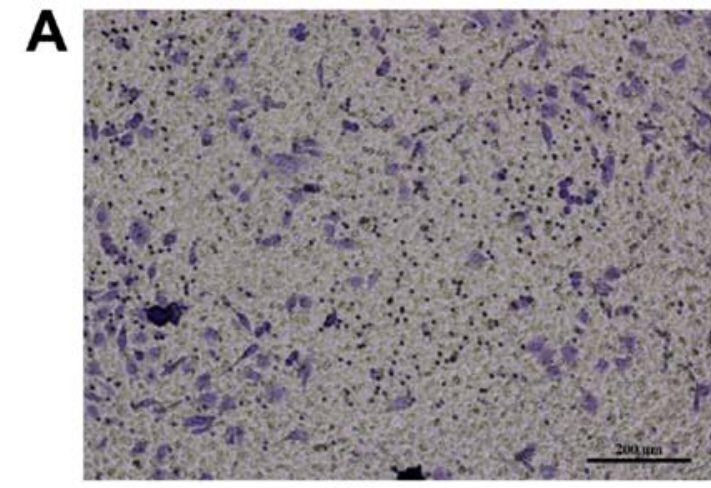

NC

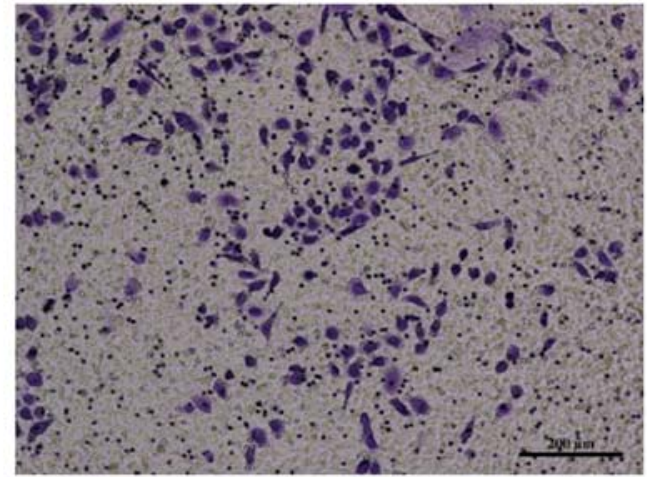

Inhibitor NC
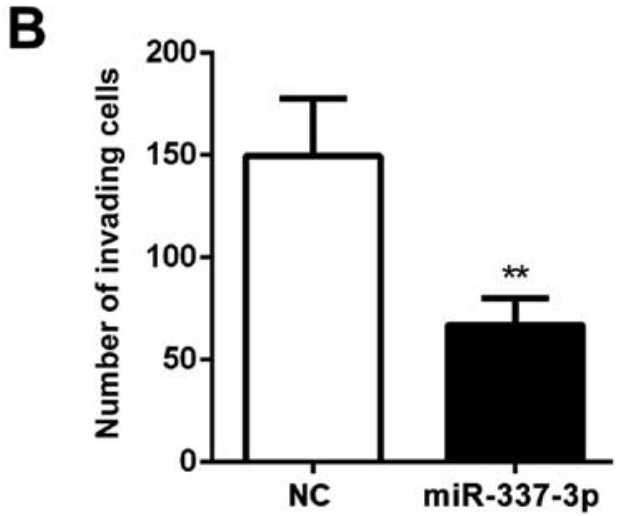

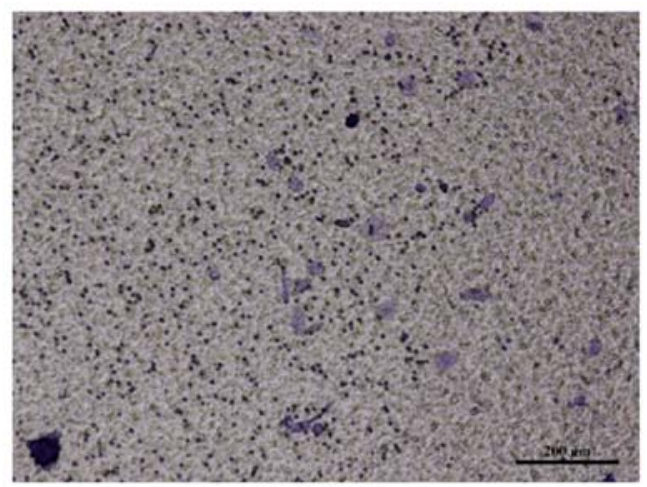

miR-337-3p

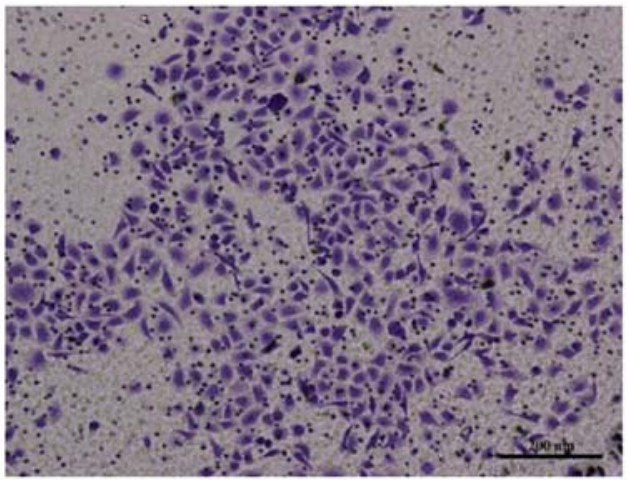

Inhibitor

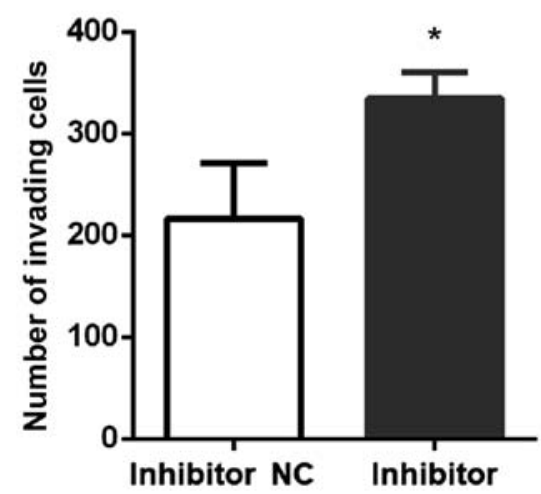

Figure 4. Overexpression of miR-337-3p inhibits the invasion of metastatic gastric tumor cells. SGC-7901 cells were transfected with control, miR-337-3p mimic, control inhibitor and miR-337-3p inhibitor and subjected to (A) Transwell invasion assays. Scale bar, $200 \mu \mathrm{m}$. (B) The results were statistically summarized. The data are expressed as the mean \pm SD of three independent transfection experiments. ${ }^{*} \mathrm{P}<0.05$ and ${ }^{* *} \mathrm{P}<0.01$. miR-337-3p, microRNA-337-3p; NC, negative control.

\section{Discussion}

Tumor metastasis is the leading cause of high mortality among patients with cancer, and the control and interruption of tumor metastasis are the key strategies in cancer treatment (1). Recent studies have identified several miRNAs that are related to tumor metastasis $(6,15,16)$. miR-337-3p was identified as a miRNA associated with gastric tumor metastasis (6). miR-337-3p was revealed to suppress the binding of myeloid zinc finger 1 to MMP14 promoter and consequently suppress the progression of gastric cancer (17). It may also play an important role in reducing tumor metastasis. However, whether miR-337-3p targets cytoskeleton-associated proteins in gastric tumor cells is unclear. In the present study, ARHGAP10 was identified as a target of miR-337-3p during the regulation of the migration of the invasive gastric tumor cell line SGC-7901.
Several mRNAs have been identified as molecules regulating gastric tumor metastasis. Both miR-370 and miR-301a have been revealed to be upregulated in metastatic gastric tumors. miR-370 is highly expressed in gastric cancer with more advanced clinical stage and targets transforming growth factor- $\beta$ receptor II and increases the oncogenic potential of gastric cancer cells (18). miR-301a downregulates the expression RUNX3 at the post-transcriptional level and promotes the invasion of gastric cancer cells (19). In addition to $\mathrm{miR}-337-3 \mathrm{p}$, miR-22, miR-610, and miR-145 were recently reported to be downregulated in gastric cancer, while their overexpression was revealed to inhibit cancer invasion and metastasis. miR-22 has been revealed to target the oncogenic gene $\mathrm{Spl}$ and inhibit the migration and invasion of SGC-7901 and NCL-N87 gastric cancer cell lines (20). However, its indirect target molecules related to cell migration are unknown. In 
A

miR-337-3p

3'--- CUUCUUUCCGUAGUAUAUCCUC---5'

ARHGAP10 3'UTR

5'---AATTATCCAAGCATATAGAATGAG--3'

miR-337-3p

$3^{\prime}$ ' cuucuuuCCGUAGUAUAUC-CUc 5'

||||$:|||||| \mid$

ARHGAP10 3'UTR 5' uncaucuGGCAUUAUAUAGAGAu 3'

miR-337-3p 3' cuUCUUUCCGUAGUAUAUC-CUc 5'

ARHGAP10 3'UTR 5' uaAUGAAUACAUCUUAUAGUGAu 3'

B
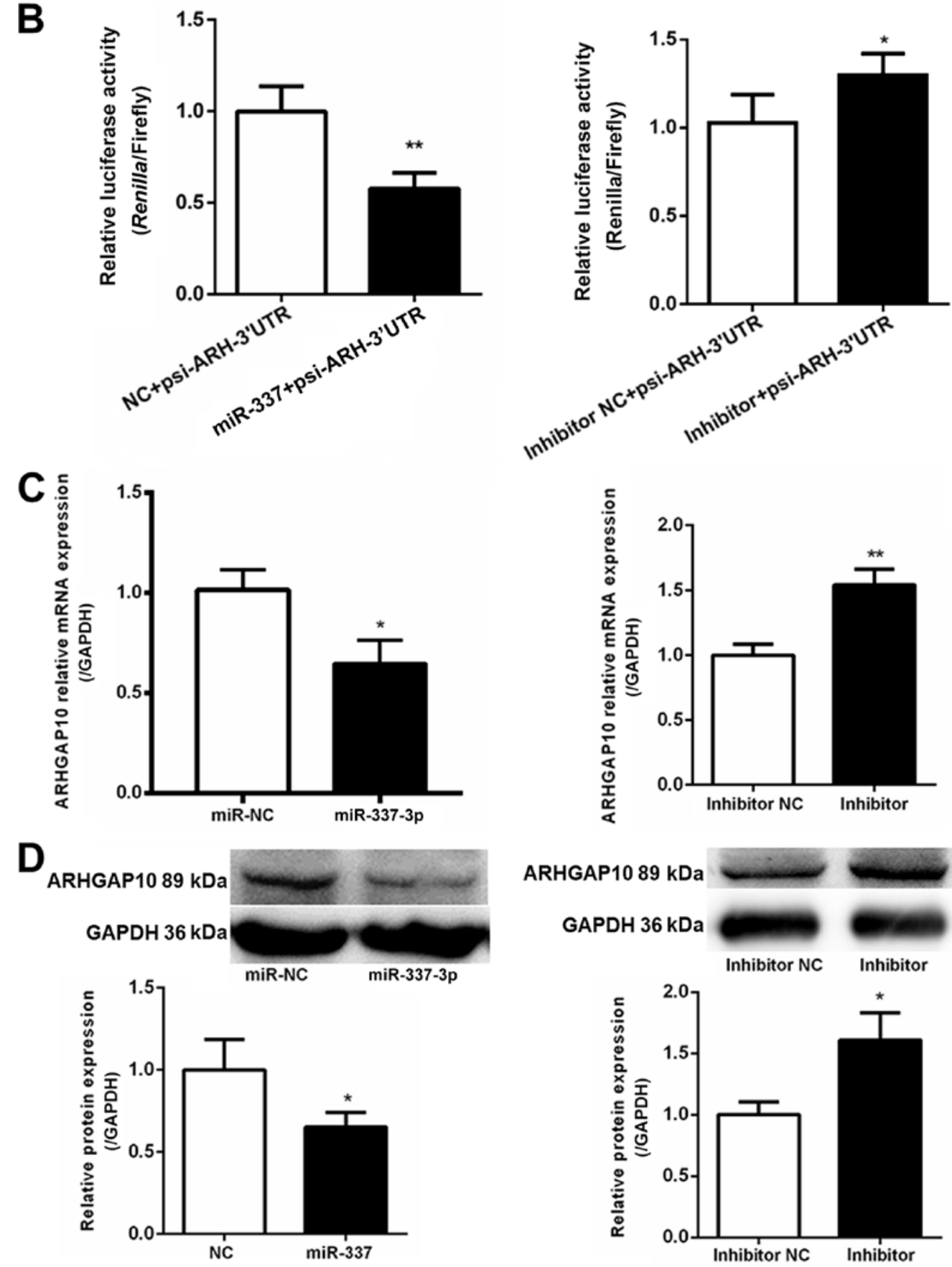

Figure 5. Binding of miR-337-3p to the 3'-UTR of ARHGAP10 and downregulation of ARHGAP10 expression by miR-337-3p in metastatic gastric tumor cells. (A) Schematic illustration revealing the potential binding sites of miR-337-3p at the 3'-UTR of ARHGAP10. miR-337-3p seed sequences and their complementary sequences on 3'-UTR are highlighted in blue. (B) pMIR-REPORT vectors containing the 3'-UTR of ARHGAP10 and control, miR-337-3p mimic, control inhibitor, or miR-337-3p inhibitor were co-transfected into $293 \mathrm{~T}$ cells. At $48 \mathrm{~h}$ after transfection, the cells were lysed and the dual-luciferase reporter assay system was used to detect luciferase activity. After transfection of SGC-7901 cells with control and miR-337-3p mimic, the cells were subjected to (C) ARHGAP10 mRNA expression analysis by reverse transcription-quantitative PCR and (D) ARHGAP10 protein expression analysis by western blotting. The data are expressed as the mean $\pm \mathrm{SD}$ of three independent transfection experiments. ${ }^{*} \mathrm{P}<0.05$ and ${ }^{* *} \mathrm{P}<0.01$. ARH, ARHGAP10; miR, microRNA; NC, negative control; UTR, untranslated region. 


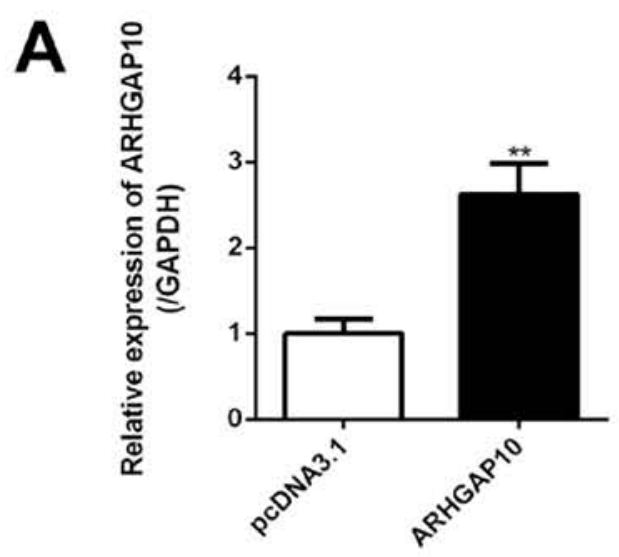

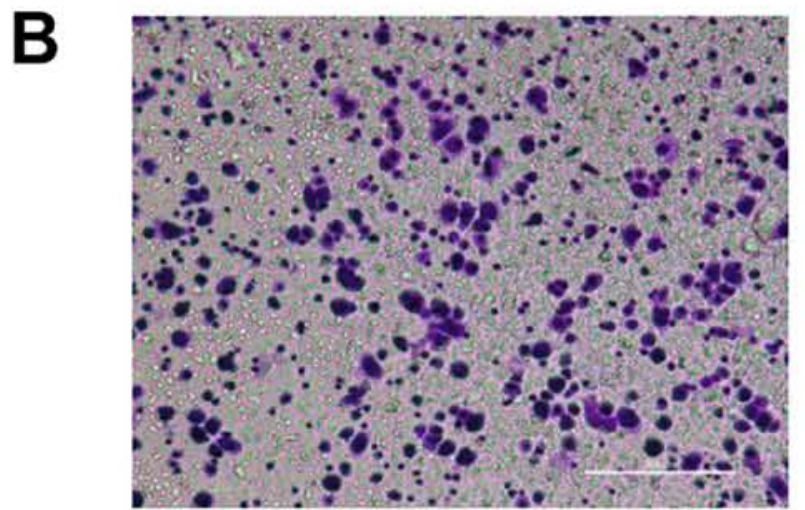

pcDNA3.1+N.C

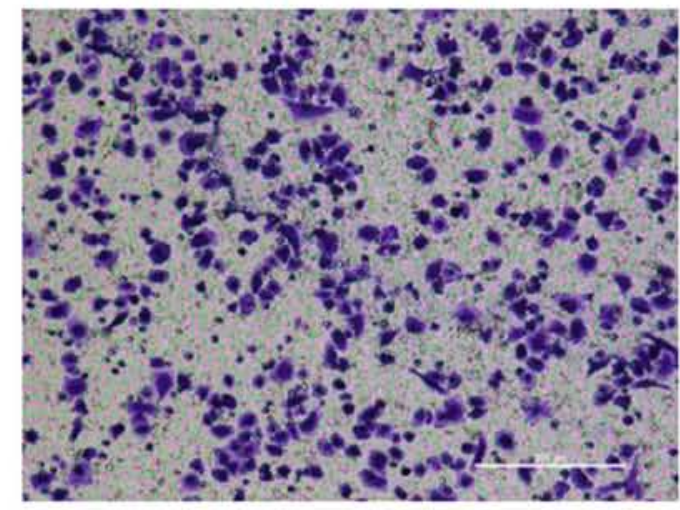

ARHGAP10+N.C

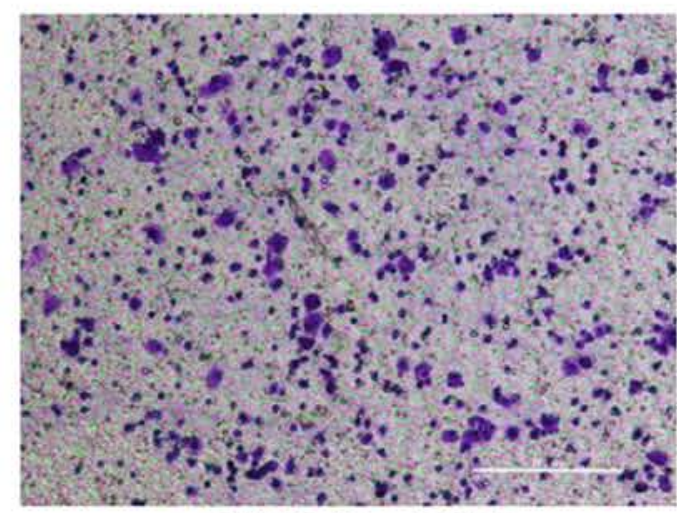

pcDNA3.1+miR337

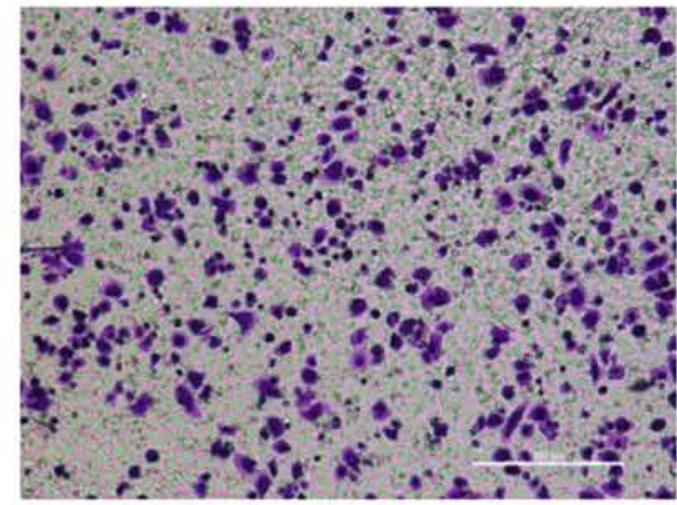

ARHGAP10+miR337

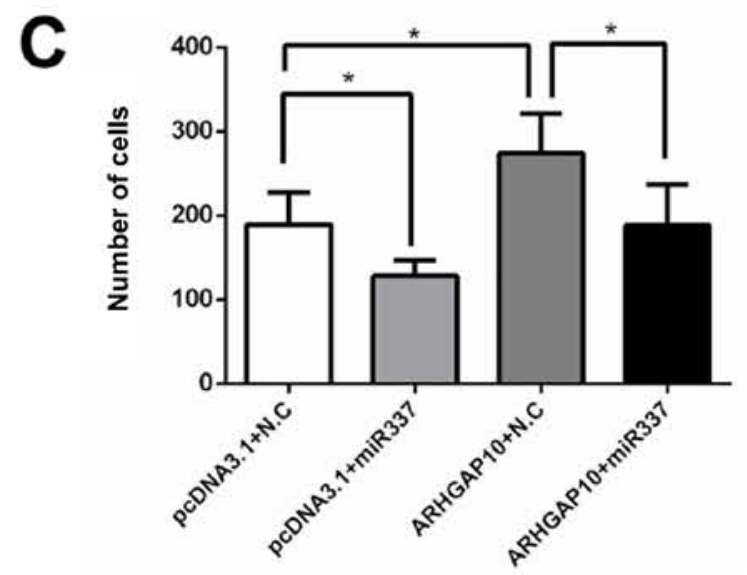

Figure 6. Migration is recovered by ARHGAP10 overexpression in metastatic gastric tumor cells. SGC-7901 cells were transfected with pcDNA3.1 and ARHGAP10, and the relative expression of ARHGAP10 was examined with reverse transcription-quantitative PCR. (A) SGC-7901 cells were co-transfected with indicated miRNA and ARHGAP10 plasmid and subjected to (B) Transwell migration assays. Scale bar, $200 \mu \mathrm{m}$. (C) Results were statistically summarized. The data are expressed as the mean \pm SD of three independent transfection experiments. ${ }^{*}<<0.05$ and ${ }^{* *} \mathrm{P}<0.01$. miR-337-3p, microRNA-337-3p; NC, negative control. 

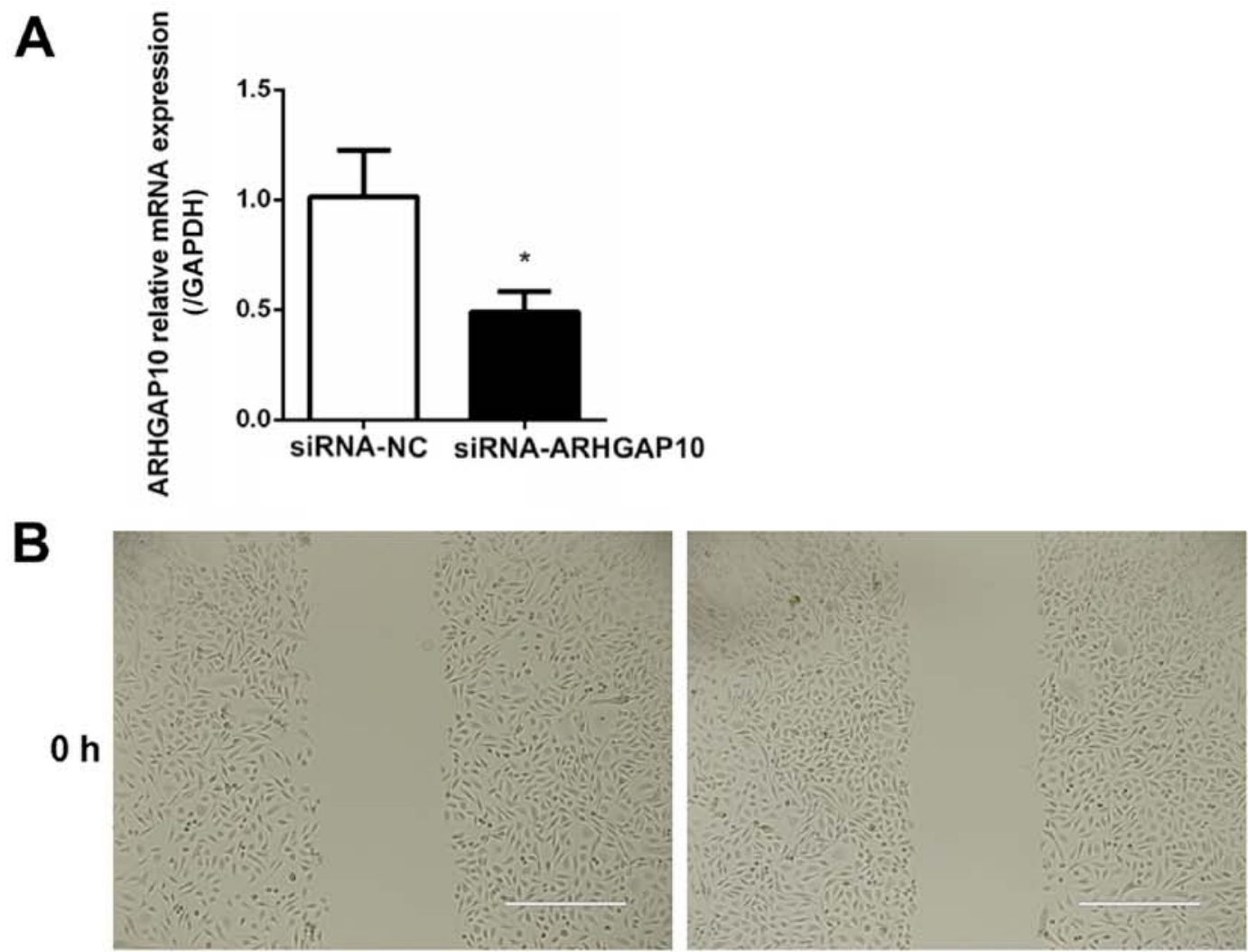

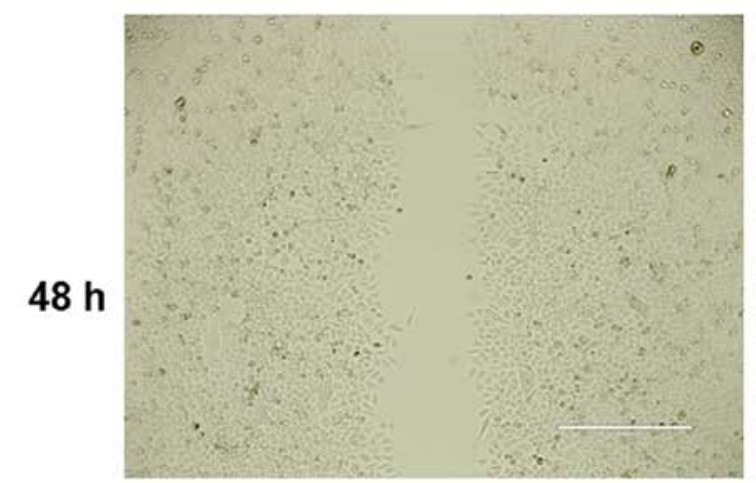

SIRNA-NC

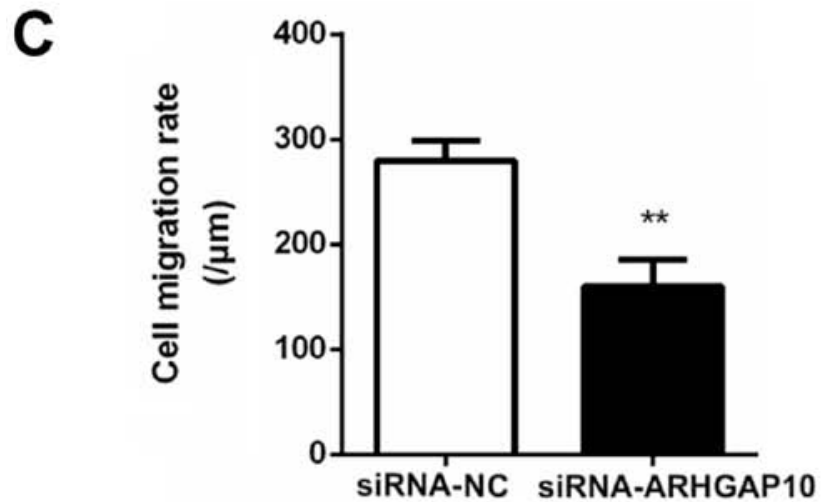

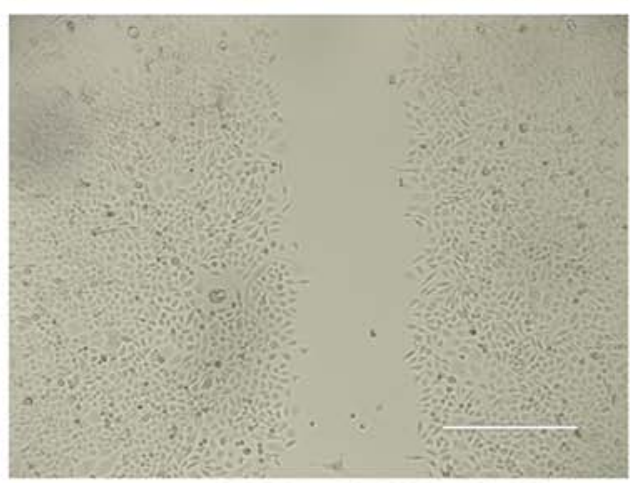

SIRNA-ARHGAP10

Figure 7. Overexpression of siRNA-ARHGAP10 results in the inhibition of ARHGAP10 mRNA expression. (A) SGC-7901 cells were transfected with siRNA-NC and siRNA-ARHGAP10, and the relative expression of ARHGAP10 was examined with reverse transcription-quantitative PCR. (B) SGC-7901 cells were transfected with siRNA-NC and siRNA-ARHGAP10. The results were amplified 40 times and wound healing assays were performed. Scale bar, $200 \mu \mathrm{m}$. (C) The results were statistically summarized. The data are presented as the mean \pm SD of three independent experiments. ${ }^{*} \mathrm{P}<0.05$ and ${ }^{* *} \mathrm{P}<0.01$. $\mathrm{NC}$, negative control; siRNA, small interfering RNA.

a previous study, we revealed that miR-22 also targets vascular endothelial cadherin in endothelial cells and interferes with the process of angiogenesis (21). miR-610 was revealed to suppress the actin-binding protein vasodilator-stimulated 
A

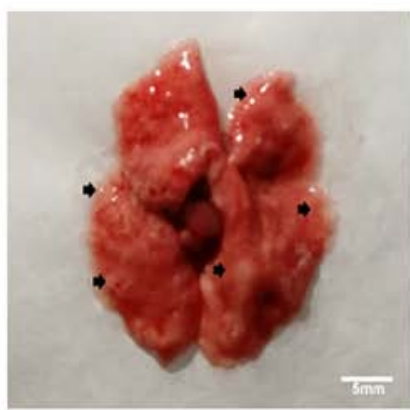

NC

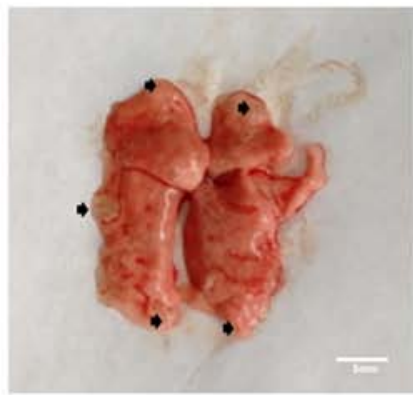

Inhibitor NC

B

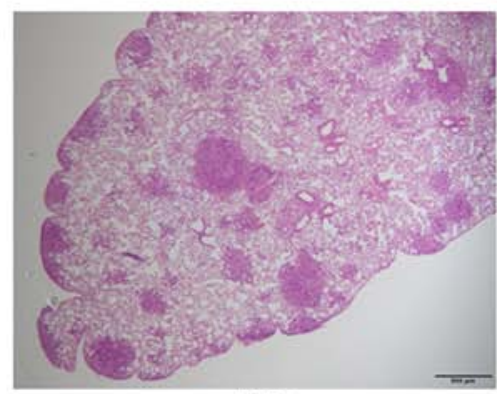

NC

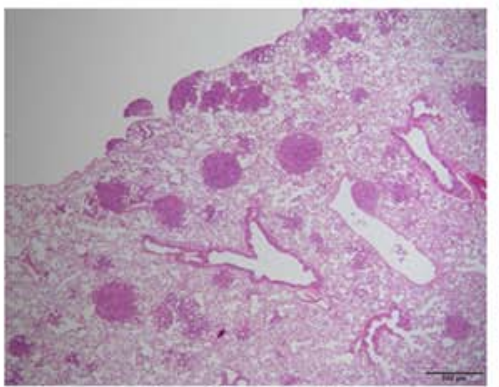

Inhibitor NC

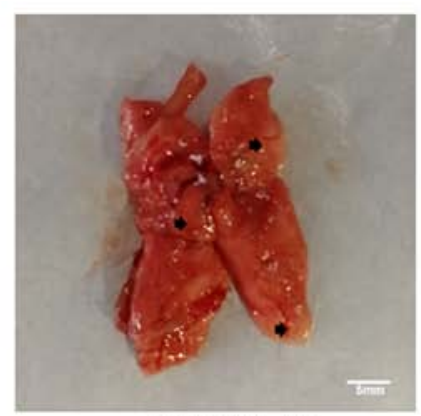

miR337-3p

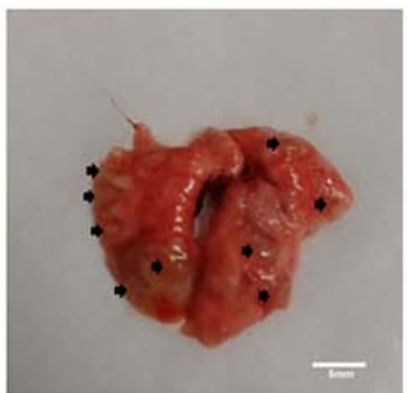

Inhibitor

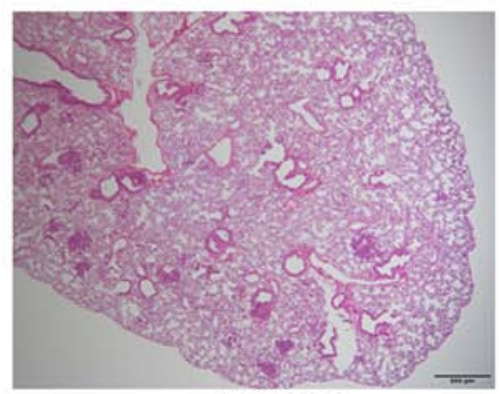

miR337-3p

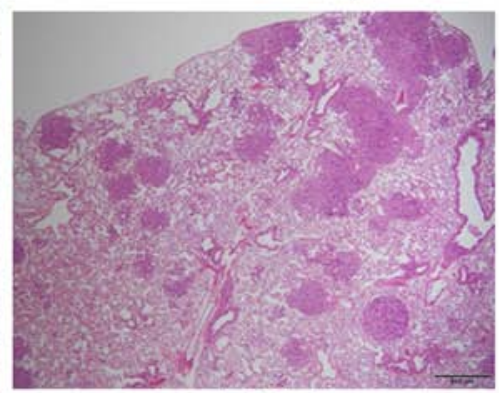

Inhibitor
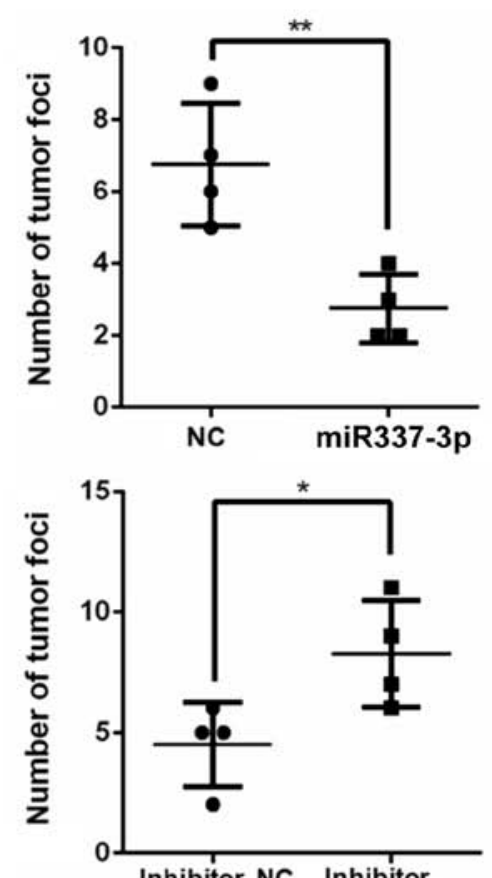

Inhibitor NC Inhibitor
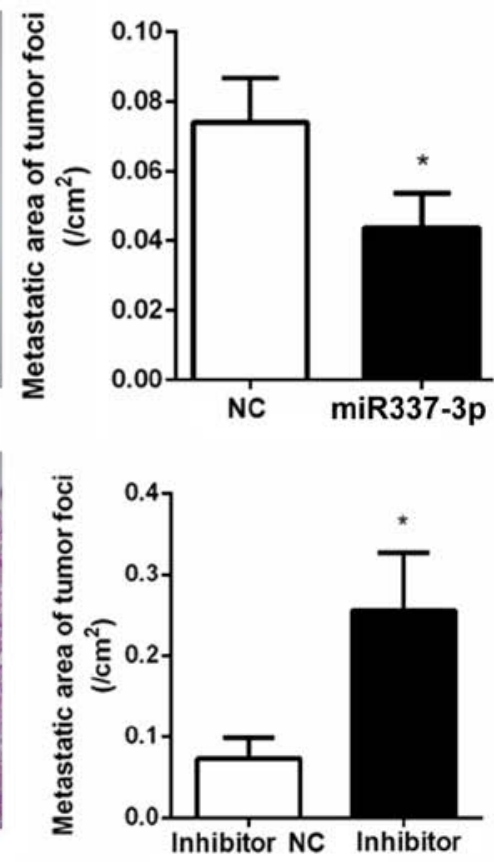

Figure 8. Overexpression of miR-337-3p results in the inhibition of gastric tumor cell metastasis in the lungs. SGC-7901 cells were transfected with control, miR-337-3p mimic, control inhibitor, and miR-337-3p inhibitor and injected into mice by tail vein. (A) After 5 weeks, lung metastatic assays were performed and the results were statistically summarized. Scale bar, $5 \mathrm{~mm}$. (B) H\&E staining of the lung tissues was performed and the results were statistically summarized. Scale bar $500 \mu \mathrm{m} .{ }^{*} \mathrm{P}<0.05$ and ${ }^{* *} \mathrm{P}<0.01$. H\&E, hematoxylin and eosin. miR-337-3p, microRNA-337-3p; NC, negative control.

phosphoprotein and inhibit the migration and invasion of gastric cancer cells (22). miR-145 was reported to markedly inhibit N-cadherin protein translation and indirectly downregulate matrix metallopeptidase 9 expression to suppress gastric cancer metastasis (23). It has been reported that mir-337-3p is also able to bind to the promoter region of MMP14 and inhibit its transcription in both gastric tumor cells and neuroblastoma cells $(7,8)$. To the best of our knowledge, whether miR-337-3p targets cytoskeleton-associated proteins in gastric tumor cells is yet unknown.
In the present study, a cytoskeleton-regulating protein, ARHGAP10, was revealed as a target molecule of miR-337-3p. ARHGAP10, also known as ARHGAP21, exhibits a Rho-GAP domain and is a cytoskeleton-associated protein. It negatively regulates the small $\mathrm{G}$ protein Rho- and Cdc42-mediated downstream signal transduction (9). There are three potential binding sites for miR-337-3p in the 3'-UTR of ARHGAP10; the results of the luciferase assay confirmed that miR-337-3p binds to the 3'-UTR of ARHGAP10, and the overexpression of miR-337-3p in SGC-7901 cells downregulates ARHGAP10 

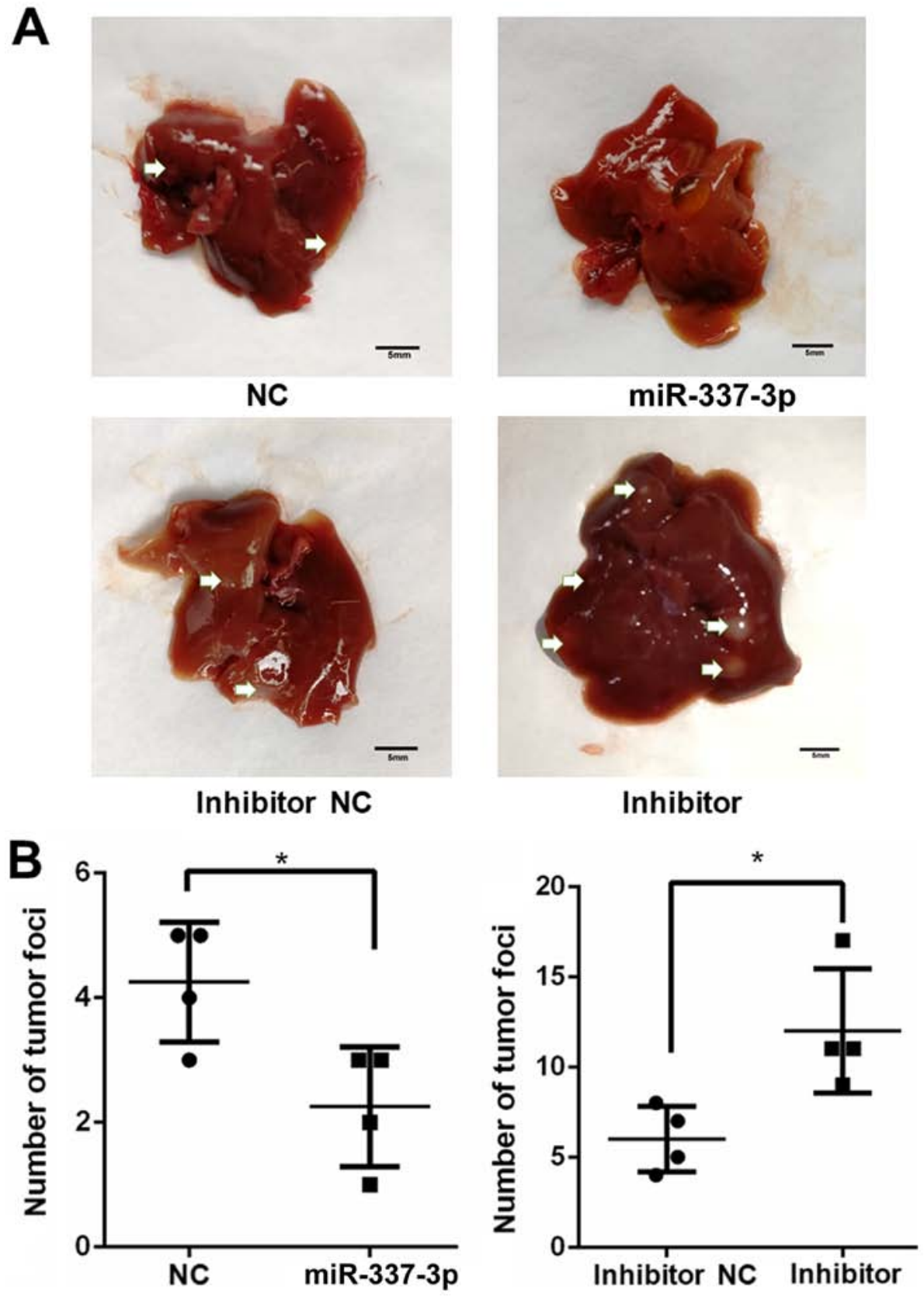

Figure 9. Overexpression of miR-337-3p results in the inhibition of gastric tumor cell metastasis in the liver. SGC-7901 cells were transfected with control, miR-337-3p mimic, control inhibitor, and miR-337-3p inhibitor and injected into mice by tail vein. (A) After 5 weeks, liver metastatic assays and (B) enumeration of tumor foci in the liver were performed. Scale bar, $5 \mathrm{~mm}$. ${ }^{*} \mathrm{P}<0.05$. miR-337-3p, microRNA-337-3p; NC, negative control.

mRNA and protein levels. These results strongly indicate that miR-337-3p targets ARHGAP10 to regulate the motility of gastric tumor cells, and that the downregulation of miR-337-3p expression in metastatic gastric cancer results in the promotion of ARHGAP10 expression to facilitate tumor cell migration and invasion.

The role of ARHGAP10 in tumor cell migration is well known. Since ARHGAP10 negatively regulates the Rho family small GTPases, it has been regarded as a tumor suppressor $(9,13)$. The depletion of ARHGAP10 expression in glioblastoma tumor cells was revealed to increase the migration ability of tumor cells (11). Studies with ovarian cancer cells have revealed that ARHGAP10 suppresses tumorigenicity (13). However, the depletion of ARHGAP10 expression in certain prostate cancer cells resulted in the inhibition of tumor cell migration (24). A recent study on breast cancer cells indicated the involvement of AHRGAP10, along with its analog ARHGAP23, in the lateral signaling pathway, which is important in cell migration. The depletion of both ARHGAP10 and ARHGAP23 by siRNA transfection resulted in the inhibition of tumor cell migration (25). In addition, ARHGAP10 was revealed to suppress tumor progression by promoting the p53-mediated apoptosis and autophagic cell death of gastric tumor cells (26). The expression level of ARHGAP10 was downregulated in lung cancer, and ARHGAP10 overexpression resulted in the suppression of the migration, proliferation, and invasion of tumor cells (27). These studies indicated that ARHGAP10 


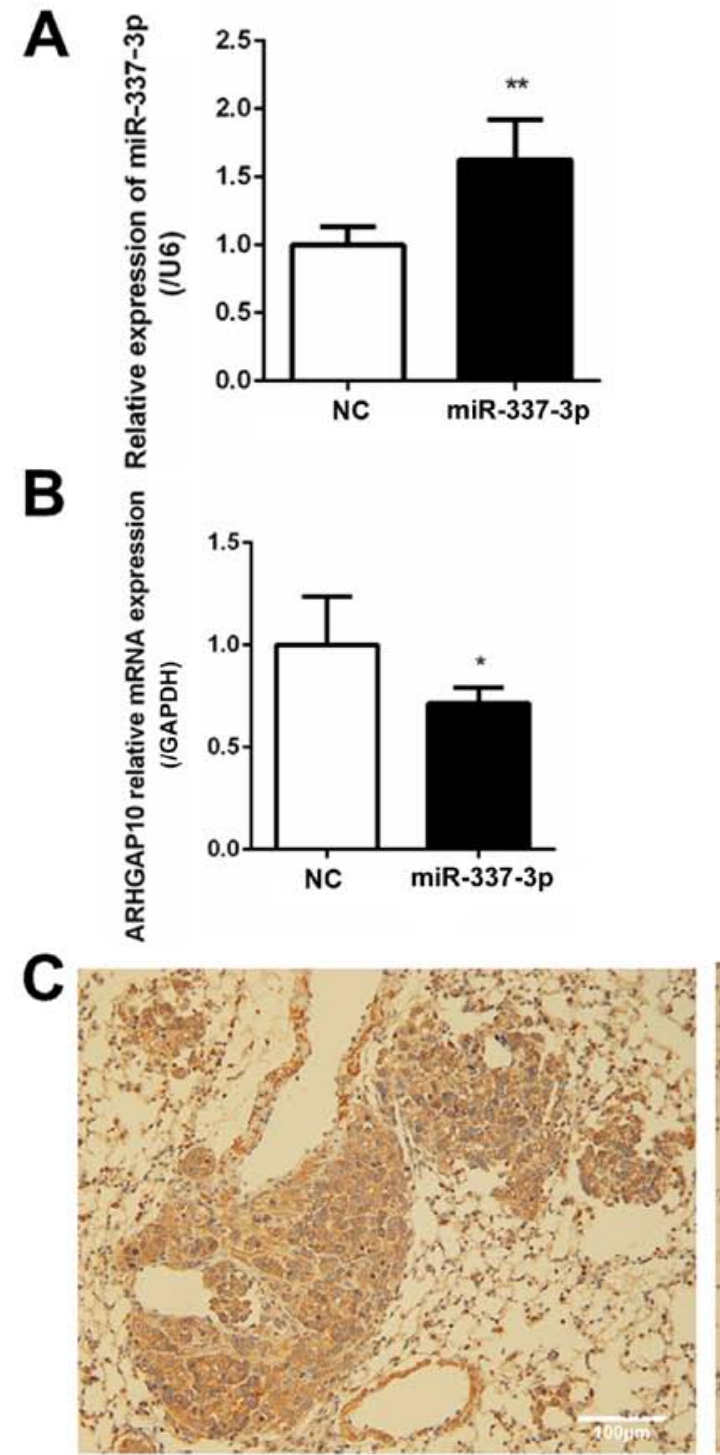

NC

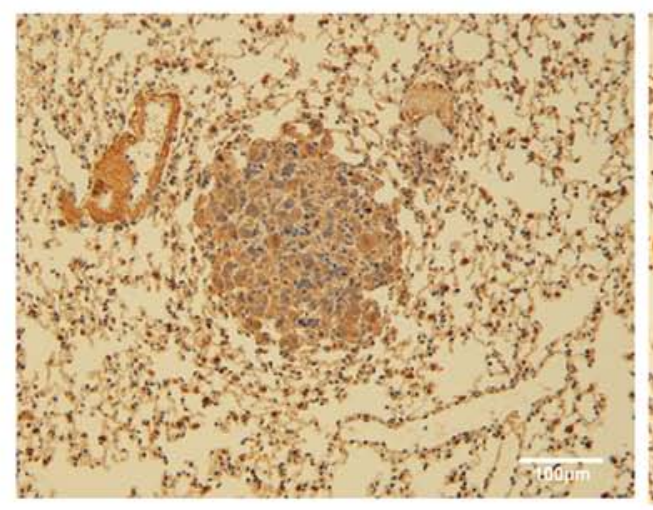

Inhibitor NC
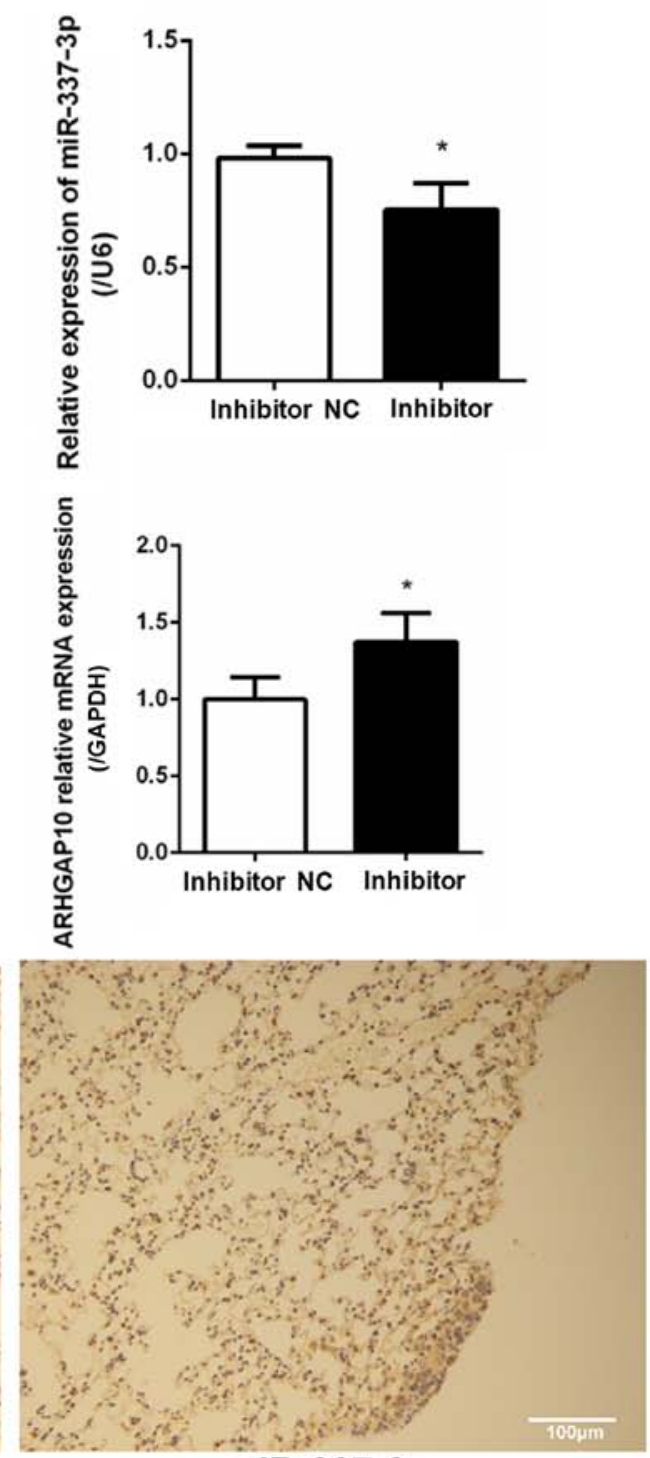

miR-337-3p

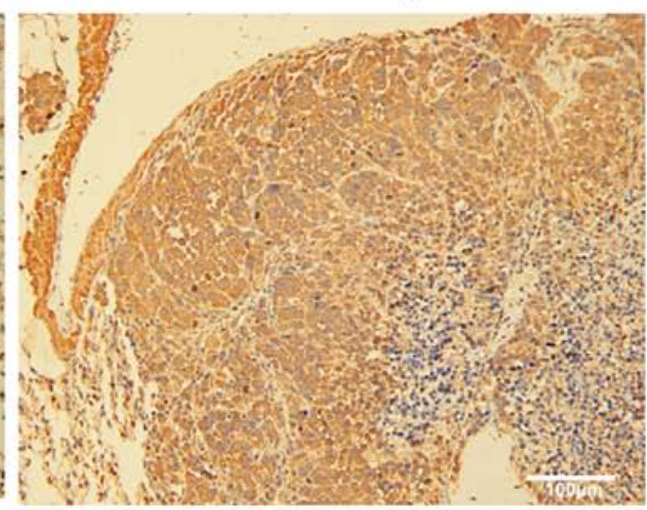

Inhibitor

Figure 10. Expression of ARHGAP10 and miR-337-3p in lung tumor foci. (A) Lung tumor foci were analyzed for the relative expression of miR-337-3p by RT-qPCR. (B) Lung tumor foci were used to assess the expression of ARHGAP10 mRNA by RT-qPCR. (C) Representative histological sections probed with a polyclonal antibody specifically for ARHGAP10 in lung tumor foci. Scale bar, $100 \mu \mathrm{m}$. ${ }^{*} \mathrm{P}<0.05$ and ${ }^{* *} \mathrm{P}<0.01$. miR-337-3p, microRNA-337-3p; NC, negative control; RT-qPCR, reverse transcription-quantitative PCR.

may play different roles in different types of tumor cells. Different cell lines used may have also contributed to the variations in results. Furthermore, the redundant functions of ARHGAP10 and ARHGAP23 may further complicate this issue. ARHGAP10 may act in a GAP-independent mechanism to regulate Rho or other signaling pathways and bind to a-catenin and regulate the recruitment of a-catenin at cell-cell contact (12). In addition, ARHGAP10 is known to 
interact with the C-terminal region of focal adhesion kinase and regulates its activity (11). The interaction of ARHGAP10 with a-tubulin results in the regulation of acetylation of tubulin during epithelial-mesenchymal transition (28). On the other hand, the interaction between ARHGAP10 and b-arrestin was revealed to inhibit GAP activity and attenuate stimulated stress fiber formation (29). Although our data clearly demonstrate the regulatory role of both miR-337-3p and ARHGAP10 in gastric tumor cell migration, further studies are required to elucidate the mechanism underlying the miR-337-3p-regulated ARHGAP10 function in the metastasis of gastric tumors.

\section{Acknowledgements}

Not applicable.

\section{Funding}

The present study was supported by the Anhui Province National Science Foundation of China (1508085MH146, ZW) and the Huazhong Agricultural University Scientific \& Technology Self-innovation Foundation (Program no. 2012RC011, GL).

\section{Availability of data and materials}

The datasets used during the present study are available from the corresponding author upon reasonable request.

\section{Authors' contributions}

ZiW, LY, GL, WG, YL, BH, MW, JuW and HZ contributed to the conception or design of the work, and the acquisition of data. QW completed the data analysis. GL, LY, BH, MW, and JuW drafted the manuscript and revised it critically for important intellectual content. All authors read and approved the final manuscript.

\section{Ethics approval and consent to participate}

All animal experiments were performed according to the guidelines of the Laboratory Animal Ethics Committee of Huazhong Agriculture University, approved by the Laboratory Animal Centre, Huazhong Agriculture University (HZAHMD-2016-037).

\section{Patient consent for publication}

Not applicable.

\section{Competing interests}

The authors declare that they have no competing interests.

\section{References}

1. Jiang WG, Sanders AJ, Katoh M, Ungefroren H, Gieseler F, Prince M, Thompson SK, Zollo M, Spano D, Dhawan P, et al: Tissue invasion and metastasis: Molecular, biological and clinical perspectives. Semin Cancer Biol 35 (Suppl): S244-S275, 2015.
2. Alizadeh AM, Shiri S and Farsinejad S. Metastasis review: From bench to bedside. Tumour Biol 35: 8483-8523, 2014.

3. Palmer TD, Ashby WJ, Lewis JD and Zijlstra A: Targeting tumor cell motility to prevent metastasis. Adv Drug Deliv Rev 63: 568-581, 2011.

4. Slezak-Prochazka I, Durmus S, Kroesen BJ and van den Berg A: MicroRNAs, macrocontrol: Regulation of miRNA processing. RNA 16: 1087-1095, 2010.

5. Kaboli PJ, Rahmat A, Ismail P and Ling KH: MicroRNA-based therapy and breast cancer: A comprehensive review of novel therapeutic strategies from diagnosis to treatment. Pharmacol Res 97: 104-121, 2015.

6. Wang Z, Wang J, Yang Y, Hao B, Wang R, Li Y and Wu Q: Loss of has-miR-337-3p expression is associated with lymph node metastasis of human gastric cancer. J Exp Clin Cancer Res 32: 76, 2013.

7. Xiang X, Mei H, Zhao X, Pu J, Li D, Qu H, Jiao W, Zhao J, Huang K, Zheng L and Tong Q: miRNA-337-3p suppresses neuroblastoma progression by repressing the transcription of matrix metalloproteinase 14. Oncotarget 6: 22452-22466, 2015.

8. Zheng L, Jiao W, Mei H, Song H, Li D, Xiang X, Chen Y, Yang F, Li H, Huang K and Tong Q: miRNA-337-3p inhibits gastric cancer progression through repressing myeloid zinc finger 1-facilitated expression of matrix metalloproteinase 14. Oncotarget 7: 40314-40328, 2016.

9. Bassères DS, Tizzei EV, Duarte AA, Costa FF and Saad ST: ARHGAP10, a novel human gene coding for a potentially cytoskeletal Rho-GTPase activating protein. Biochem Biophys Res Commun 294: 579-585, 2002.

10. Dubois T and Chavrier P.: ARHGAP10, a novel RhoGAP at the cross-road between ARF1 and Cdc42 pathways, regulates Arp2/3 complex and actin dynamics on Golgi membranes. Med Sci (Paris) 21: 692-694, 2005 (In French).

11. Bigarella CL, Borges L, Costa FF and Saad ST: ARHGAP21 modulates FAK activity and impairs glioblastoma cell migration. Biochim Biophys Acta 1793: 806-816, 2009.

12. Sousa S, Cabanes D, Archambaud C, Colland F, Lemichez E, Popoff M, Boisson-Dupuis S, Gouin E, Lecuit M, Legrain P and Cossart P: ARHGAP10 is necessary for alpha-catenin recruitment at adherens junctions and for Listeria invasion. Nat Cell Biol 7: 954-960, 2005.

13. Luo N, Guo J, Chen L, Yang W, Qu X and Cheng Z: ARHGAP10, downregulated in ovarian cancer, suppresses tumorigenicity of ovarian cancer cells. Cell Death Dis 7: e2157, 2016.

14. Livak KJ and Schmittgen TD: Analysis of relative gene expression data using real-time quantitative PCR and the 2(-Delta Delta C(T)) method. Methods 25: 402-408, 2001.

15. Li X, Xu M, Ding L and Tang J: miR-27a: A novel biomarker and potential therapeutic target in tumors. J Cancer 10: 2836-2848, 2019.

16. Li N, Xie C and Lu N: Crosstalk between Hippo signalling and miRNAs in tumour progression. FEBS J 284: 1045-1055, 2017.

17. Zheng LD, Jiao WJ, Mei H, Song HJ, Li D, Xiang X, Chen YJ, Yang F, Li HH, Huang K and Tong Q: miRNA-337-3p inhibits gastric cancer progression through repressing myeloid zinc finger 1-facilitated expression of matrix metalloproteinase 14. Oncotarget 7: 40314-40328, 2016.

18. Lo SS, Hung PS, Chen JH, Tu HF, Fang WL, Chen CY, Chen WT, Gong NR and Wu CW: Overexpression of miR-370 and downregulation of its novel target TGF $\beta$-RII contribute to the progression of gastric carcinoma. Oncogene 31: 226-237, 2012.

19. Wang M, Li C, Yu B, Su L, Li J, Ju J, Yu Y, Gu Q, Zhu Z and Liu B: Overexpressed miR-301a promotes cell proliferation and invasion by targeting RUNX3 in gastric cancer. J Gastroenterol 48: 1023-1033, 2013

20. Guo MM, Hu LH, Wang YQ, Chen P, Huang JG, Lu N, He JH and Liao CG: miR-22 is down-regulated in gastric cancer, and its overexpression inhibits cell migration and invasion via targeting transcription factor Sp1. Med Oncol 30: 542, 2013.

21. Gu W, Zhan H, Zhou XY, Yao L, Yan M, Chen A, Liu J, Ren X, Zhang X, Liu JX and Liu G: MicroRNA-22 regulates inflammation and angiogenesis via targeting VE-cadherin. FEBS Lett 591: 513-526, 2017.

22. Wang J, Zhang J, Wu J, Luo D, Su K, Shi W, Liu J, Tian Y and Wei L: MicroRNA-610 inhibits the migration and invasion of gastric cancer cells by suppressing the expression of vasodilator-stimulated phosphoprotein. Eur J Cancer 48: 1904-1913, 2012. 
23. Gao L, Ren W, Chang S, Guo B, Huang S, Li M, Guo Y, Li Z, Song T, Zhi K and Huang C: Downregulation of miR-145 expression in oral squamous cell carcinomas and its clinical significance. Onkologie 36: 194-199, 2013.

24. Lazarini M, Traina F, Machado-Neto JA, Barcellos KS Moreira YB, Brandão MM, Verjovski-Almeida S, Ridley AJ and Saad ST: ARHGAP21 is a RhoGAP for RhoA and RhoC with a role in proliferation and migration of prostate adenocarcinoma cells. Biochim Biophys Acta 1832: 365-374, 2013.

25. Zhang L, Luga V, Armitage SK, Musiol M, Won A, Yip CM, Plotnikov SV and Wrana JL: A lateral signalling pathway coordinates shape volatility during cell migration. Nat Commun 7 : $11714,2016$.

26. Li B, Wang L, Li Z, Wang W, Zhi X, Huang X, Zhang Q, Chen Z, Zhang X, He Z, et al: miR-3174 contributes to apoptosis and autophagic cell death defects in gastric cancer cells by targeting ARHGAP10. Mol Ther Nucleic Acids 9: 294-311, 2017.

27. Teng JP, Yang ZY, Zhu YM, Ni D, Zhu ZJ and Li XQ: The roles of ARHGAP10 in the proliferation, migration and invasion of lung cancer cells. Oncol Lett 14: 4613-4618, 2017.
28. Barcellos KS, Bigarella CL, Wagner MV, Vieira KP, Lazarini M, Langford PR, Machado-Neto JA, Call SG, Staley DM, Chung JY, et al: ARHGAP21 protein, a new partner of alpha-tubulin involved in cell-cell adhesion formation and essential for epithelial-mesenchymal transition. J Biol Chem 288: 2179-2189, 2013.

29. Anthony DF, Sin YY, Vadrevu S, Advant N, Day JP, Byrne AM, Lynch MJ, Milligan G, Houslay MD and Baillie GS: $\beta$-Arrestin 1 inhibits the GTPase-activating protein function of ARHGAP21, promoting activation of RhoA following angiotensin II type 1A receptor stimulation. Mol Cell Biol 31: 1066-1075, 2011.

(i) $\Theta$ This work is licensed under a Creative Commons Attribution-NonCommercial-NoDerivatives 4.0 International (CC BY-NC-ND 4.0) License. 